\title{
Adsorption-catalytic Purification of Gas Mixtures from Sulphur Dioxide by Sorbent of Phosphoric Production Wastes
}

\author{
Almaz Bahitovich Kaldybayev ${ }^{1}$, Birzhan Sardarovich Shakirov ${ }^{1}$, \\ Raziya Adilbekovna Isayeva ${ }^{1}$, Kurmanbek Tazhmahanbetovich Zhantasov ${ }^{1}$ \\ and Mikhail Rodionovich Baklanov ${ }^{2}$
}

\author{
${ }^{1}$ M. Auezov South Kazakhstan State University, 160012 \\ Republic of Kazakhstan, Shymkent city, Tauke khan, 5 \\ ${ }^{2}$ Interuniversity Micro-Electronics Center at Leuven, Kapeldreef 75, B-3001, Leuven, Belgium
}

DOI: http://dx.doi.org/10.13005/bbra/1931

(Received: 25 September 2015; accepted: 02 November 2015)

\begin{abstract}
This work is aimed at solving the problem on sorption purification of waste gases from sulfur dioxide on the wastes of phosphoric industry, i.e. thermophosphorus slags (TPhS). The solution of this problem is implemented by the new technical result, which is caused in increasing the depth of treatment by sulfur dioxide. Essential features of the claimed technical solution are the sorption purification of sulfur dioxide from waste gases on sorbent, containing layer of the granular TPhS. The experimental results showed that the highest activity of the sorbent, calcined at $500^{\circ} \mathrm{C}$, is manifested at a temperature of sorption of $200{ }^{\circ} \mathrm{C}$. With further increase of the process temperature, the degree of sorption does not change and duration of work of the sorbent is reduced.
\end{abstract}

Key words: Thermophosphorus slag, adsorption of $\mathrm{SO}_{2}$, catalysis, calcination, chemisorptions, activation of metal oxides.

In the modern period a treatment of emissions from harmful substances for the majority of industrial enterprises is one of the basic measures on protection of air basin. Neutralization of wastes supposes either removal of harmful impurities from inert gas-carrier or turning them into harmless substances. Both principles can be implemented through a variety of physical and chemical processes, implementations of which require certain conditions for the gas cleaning technology.

Due to the formation of large amounts as wastes, sulfur dioxide becomes one of the main

\footnotetext{
* To whom all correspondence should be addressed.
}

gases that pollute the atmosphere. The greatest danger is the pollution by sulfur compounds which are released into the atmosphere at combustion of coal, oil and natural gas, as well as metal smelting and sulfuric acid production (Ling et al. 2010), which falls back to the earth in the form of acid rain. The acid rains have destructive effects on the biosphere (Jin-an et al. 1999).

The most promising, for the purification of waste gases from sulfur dioxide is the use of metals, especially alkaline earth or amphoteric metals oxides or carbonates as an adsorbent (Bennici et al., 2003; Smirnov et al., 2005; Bretschneider and Kurfurst, 1989; Li et al., 2004; Chmielarz et al., 2006). However, a special preparation of individual metal oxides significantly complicates and makes the process more expensive. 
That's way, the use of more available and cheap natural or recycled materials for these purposes should be considered as beneficial and appropriate.

Currently, one of the acceptable methods of gas emissions purification from harmful impurities, in particular sulfur dioxide is the adsorption method with the use of phosphorus waste production, developed by the authors of this research.

\section{EXPERIMENTAL}

\section{Materials and methods}

The objects and methods have been selected, the issues of purification of the flue gas emissions with the use termophosphorus slag have been considered to perform the research work.

The installation for carrying out of the research on purification of gas mixtures from sulfur dioxide on the basis of the laboratory has been designed and created.

The installation is intended for carrying out experiments on the purification of model gas mixture from sulfur dioxide (Figure 1). It consists of the following parts:

a) A part for preparation of the model gas mixture;

b) A part for carrying out the experiments on the purification of the gas mixture by solid sorbent.

The model gas mixture is prepared by mixing of gaseous sulfur dioxide, supplied from balloon ${ }^{1}$ through a gasholder with layer of oil, by preventing dissolution of sulfur dioxide in water ${ }^{2}$. A constant level of water in the gasholder is kept up by controlling water layer in the water $\operatorname{tank}^{3}$. The gas is mixed with air, supplied by a compressor ${ }^{4}$. The feed rate of sulfur dioxide and air is regulated by appropriate rheometers ${ }^{5,6}$. The gas mixture, produced in a mixer ${ }^{7}$ is directed to the reactor $^{11}$, heated by a furnace ${ }^{12}$. The temperature in the reactor is regulated by a potentiometer ${ }^{13}$. The installation is equipped with samplers ${ }^{8,14}$.

When it is necessary to prepare the model gas mixture with vapors, a certain amount of water with the help of a syringe in a gas supply line ${ }^{9}$ is supplied and is heated by a furnace ${ }^{10}$ and supplied to the mixer7. The gas mixture is supplied to the reactor from below. The reactor consists of a cylindrical glass (depending on operating temperature from molybdenum or quartz glass) vessel with a spherical perforated partition wall in the lower part and is equipped with a thermocouple well, it has bottom and top side tubes for supplying and discharging the gas mixture.

\section{Preparation of sorbent}

The thermal treatment of thermophosphorus slag has been carried out in the electric stove with automatic temperature regulation. The period of preliminary calcination was considered as equal to 2 hours. The weight of thermophosphoric slag has been dried in thermostat at $120-150^{\circ} \mathrm{C}$ and then has been placed into the stove, and started heating. Upon reaching the predetermined temperature the heating time has been set. Prepared in such way sorbent has been stored in glass vessels with a glass stopper, i.e. there was not access to moisture and air.

\section{Sorbent characterization}

The results of mineralogical, $\mathrm{X}$-ray and infrared spectroscopic analyses show that the thermophosphorous slag does not practically contain the individual oxides mixture. The initial sorbent, that has a light gray color, with a specific gravity of 2,86 g/ $\mathrm{cm}^{3}$, hygroscopic moisture of $0,37 \%$, a bulk density of $1,74 \mathrm{~g} / \mathrm{cm}^{3}$ and grain size of $0,074-2,5 \mathrm{~mm}$, is subjected to the pre-grinding for obtaining the homogeneous mass and more reactive surface. Chemical composition of termophosphorus slag is shown in Table 1 and an electronic image is presented in Figure 2.

The studied sorbent in amount of $20 \mathrm{~g}$ and spherical nozzles are loaded into the reactor through the top side of tube. In the load condition the sorbent occupies the inter-packed space in the reactor. The gas mixture supplied under the slight excessive pressure, passing through the perforated partition wall in the reactor, tends to the upward by the way of the low effort closer to the outer wall of the reactor. At that, exerting pressure on the spherical nozzles from the side of walls, it is rolled up from the walls in radial direction. At that the sorbent occupies freed after the shift of the nozzle space. Multiple repetition of such displacement of the nozzle and sorbent simulates "a boiling bed". Meanwhile, since level of the nozzle is considerably higher than level of the sorbent in the inter-packed space, entrainment of the adsorbent by the escaping gas mixture is 
negligible. Furthermore, the upper lateral aperture, by which the purified gas mixture enters, is filled with a glass fiber, which acts as a reflective trap.

$20 \mathrm{~g}$ of the freshly calcined thermophosphorus slag by $0.25-0.50 \mathrm{~mm}$ fraction has been placed into the reactor. The gas mixture has been passed through the adsorbent layer at the constant volume velocity in $9000 \mathrm{~h}^{-1}$ and temperature in 100, 150, 200, 300, 400, 500, 600, 700, $800^{\circ} \mathrm{C}$. The results are presented in Table 2 .

\section{RESULTSAND DISCUSSION}

The character of the sorption on the samples, differing by the mode of preliminary heat treatment is different. Thus, the maximum degree of adsorption on these adsorbents is observed at different temperatures. In the case of the sorbent, calcined at $500^{\circ} \mathrm{C}$, the maximum cleaning degree is observed at a temperature of $200{ }^{\circ} \mathrm{C}$, and on a sample with calcination of $800{ }^{\circ} \mathrm{C}, 400-500{ }^{\circ} \mathrm{C}$, respectively (Figure 4). They are also differed by the magnitude of dynamic capacity. Apparently, it is caused by the fact that various compounds, entering into the composition of phosphorus slag wastes participate in the process of sorption.

For the process temperature of $200^{\circ} \mathrm{C}$ on the sorbent, calcined at $800{ }^{\circ} \mathrm{C}$, sulphur dioxide concentration of $9,65 \%$, a sulphur - capacitance is equal to $2,90 \% \mathrm{wt}$. With the increase of the process temperature up to $500^{\circ} \mathrm{C}$, a sulphur - capacitance increases up to $3,36 \%$ wt. However, further increasing the temperature of the experiment up to $600{ }^{\circ} \mathrm{C}$ a sulphur - capacitance decreases up to $1,72 \%$ wt. It is probably occurs due to oversaturation of the sorbent as a result of oxidation of sulphide compounds.

Calcination temperature of the sorbent,

Table 1. Chemical composition of the thermophosphorus slag

\begin{tabular}{llc}
\hline No & Chemical formula & Content in \% mass \\
\hline 1 & $\mathrm{SiO}_{2}$ & 32.67 \\
2 & $\mathrm{Al}_{2} \mathrm{O}_{3}$ & 4.90 \\
3 & $\mathrm{TiO}_{2}$ & 0.25 \\
4 & $\mathrm{Fe}_{2} \mathrm{O}_{3}$ & 3.90 \\
5 & $\mathrm{CaO}$ & 41.92 \\
6 & $\mathrm{MgO}$ & 3.85 \\
7 & $\mathrm{P}_{2} \mathrm{O}_{5}$ & 1.81 \\
8 & $\mathrm{SO}_{3}$ & 0.90 \\
9 & $\mathrm{FeO}+\mathrm{MnO}$ & 6.91 \\
10 & $\mathrm{~K}_{2} \mathrm{O}$ & 2.89 \\
& $\mathrm{Total}$ & 100 \\
\hline
\end{tabular}

Table 2. The influence of calcination temperature of the thermophosphorus slag on the degree of purification of the model gas mixture and dynamic capacity of the sorbent

\begin{tabular}{|c|c|c|c|c|}
\hline No & $\begin{array}{l}\text { Temperature of the } \\
\text { experiment, }{ }^{\circ} \mathrm{C}\end{array}$ & $\begin{array}{l}\text { Purification degree } \\
\text { from sulfur dioxide, } \\
\text { \% vol. }\end{array}$ & $\begin{array}{c}\text { Amount of sorbed dioxide from } \\
\text { the beginning of adsorption } \\
\text {,\% mass }\end{array}$ & $\begin{array}{l}\text { Reduction time of the } \\
\text { purification degree till } \\
0-10 \% \text {, min. }\end{array}$ \\
\hline \multicolumn{5}{|c|}{ a) calcination temperature is $500^{\circ} \mathrm{C}$} \\
\hline 1 & 100 & 32 & 2.73 & 25 \\
\hline 2 & 150 & 38.5 & 4.42 & 40 \\
\hline 3 & 200 & 50 & 6.82 & 55 \\
\hline 4 & 300 & 52.3 & 6.91 & 45 \\
\hline \multicolumn{5}{|c|}{ b) calcination temperature is $800^{\circ} \mathrm{C}^{*}$} \\
\hline 5 & 200 & 35 & 2.90 & 50 \\
\hline 6 & 300 & 35 & 3.02 & 30 \\
\hline 7 & 400 & 46 & 8.45 & 65 \\
\hline 8 & 500 & 55 & 8.36 & 55 \\
\hline 9 & 600 & 35 & 1.72 & 20 \\
\hline 10 & 700 & 35 & 1.72 & 20 \\
\hline 11 & 800 & 35 & 1.65 & 15 \\
\hline \multicolumn{5}{|c|}{ c) calcination temperature is $1000^{\circ} \mathrm{C}$} \\
\hline 12 & 200 & 60 & 7.74 & 60 \\
\hline
\end{tabular}

Duration of the calcination in all experiments is 2 hours 
which equal to $1000{ }^{\circ} \mathrm{C}$ allows to obtain a more active sorbent. It manifests $60 \%$ degree of cleaning even at $200{ }^{\circ} \mathrm{C}$. However, high energy costs by calcination are not justified at an insignificant difference between the degrees of cleaning in the presence of sorbents, calcined at $500{ }^{\circ} \mathrm{C}$ and at $1000{ }^{\circ} \mathrm{C}$. With the increase of calcination temperature from $500^{\circ} \mathrm{C}$ up to $1000^{\circ} \mathrm{C}$, a sulphurcapacitance increases from 6,32 up to 7,74\% wt.

Thus, a preliminary search of optimum conditions of heat-treatment of the sorbent allows to consider that the most suitable temperature of ore calcination is $500{ }^{\circ} \mathrm{C}$ (Fig.3), the cleaning process $-200^{\circ} \mathrm{C}$ or $800^{\circ} \mathrm{C}$ at the process temperature of cleaning of $500^{\circ} \mathrm{C}$.
The experimental results show that the highest activity of the sorbent calcined at $500^{\circ} \mathrm{C}$ is developed at the sorption temperature in $200^{\circ} \mathrm{C}$ (Fig. 4). At the further increase of temperature the sorption degree is not changed, and working time of the sorbent is reduced. This phenomenon may be the result of influence of adsorption-desorption factors on the process. From the practical point of view, low temperature is more convenient for development of technological scheme of the process. Consequently, temperature in $200^{\circ} \mathrm{C}$ can be considered as the most appropriate temperature of the process.

Figure 4. Dependence of the initial degree of the gas purification on the experiment temperature

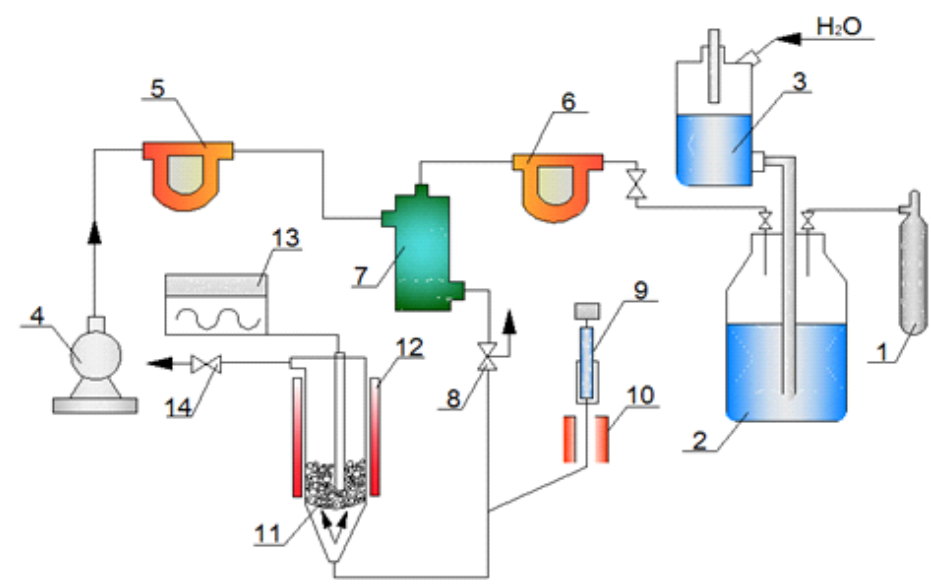

1-tank balloon with liquid sulfur dioxide; 2-gasholder; 3-water drive bottle; 4-compressor; 5, 6-rheometers; 7-mixer; 8, 14- samplers; 9-syringe; 10-furnace; 11- reactor; 12-electric stove; 13-potentiometer for measuring the temperature.

Fig. 1. Schematic technological diagram of the laboratory installation for the purifying of gas mixture from sulfur dioxide

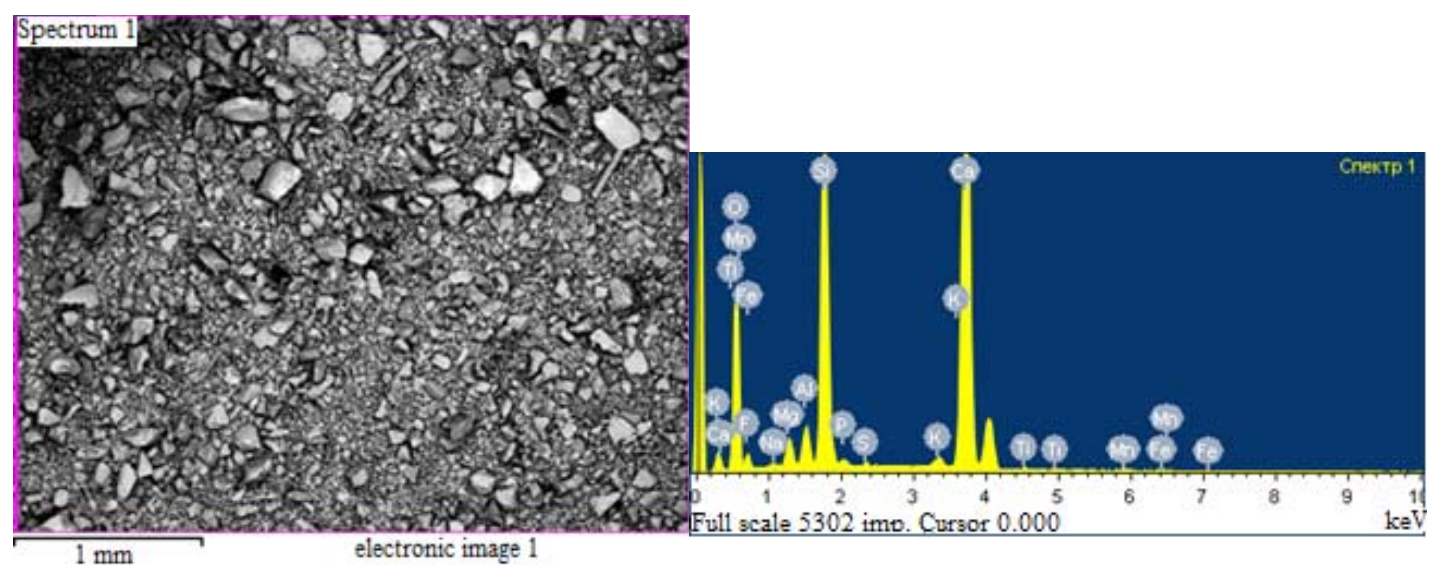

Fig. 2. Electronic image of the thermophosphorus slag 
Bond strength of the adsorbed molecules with surface complex depends on the nature of its connection with substrate. It is the strongest one in the case of $\mathrm{Fe}_{2} \mathrm{O}_{3}-\mathrm{MgO}$ compositions (He et al., 2008; He et al., 2004; Eid and Ammar, 2011), and in the case of $\mathrm{Fe}_{2} \mathrm{O}_{3}-\mathrm{SiO}_{2}$ (Przepiórski et al., 2012) it is the weakest one.

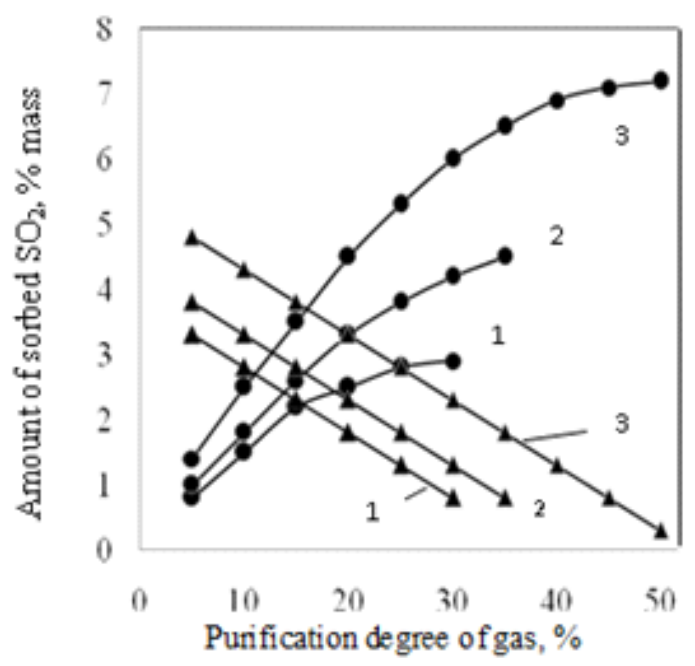

Amount of sorbed $\mathrm{SO}_{2}, \%$ mass

Purification degree of gas, \%

The experiment's conditions:

calcination temperature of the sorbent is $500^{\circ} \mathrm{C}$, concentration of $\mathrm{SO}_{2}$ is $0,65 \%$

1 - temperature of the experiment is $100^{\circ} \mathrm{C}$;

2 - temperature of the experiment is $150^{\circ} \mathrm{C}$;

3 - temperature of the experiment is $200^{\circ} \mathrm{C}$

Fig. 3. Change of the purification degree and amount of the sorbed $\mathrm{SO}_{2}$ in time for

different temperatures of the experiment

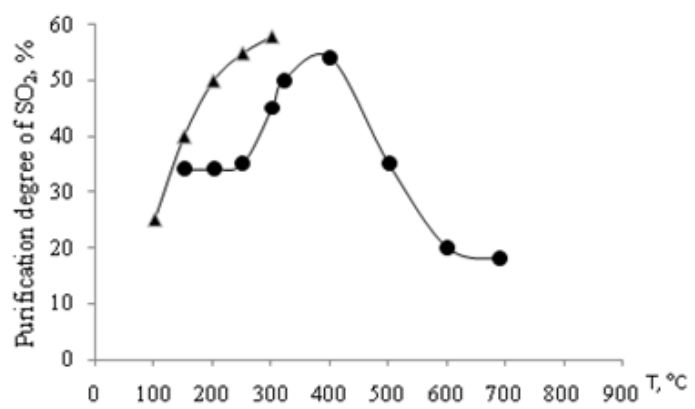

1 -calcination temperature is $800^{\circ} \mathrm{C}, 2$ - calcination temperature is $500^{\circ} \mathrm{C}$.

Fig. 4. Dependence of the initial degree of the gas purification on the experiment temperature
Despite the fact that concentration of iron in the samples has not been changed, and specific surface was the greatest for silica gel, the sorption activity of $\mathrm{F}_{e 2} \mathrm{O}_{3}-\mathrm{SiO}_{2}$ system was the lowest. From the works (Yao et al., 2008) it follows that mainly surface iron complexes with distorted octahedral symmetry of coordination sphere are formed in $\mathrm{Fe}_{2} \mathrm{O}_{3}-\mathrm{SiO}_{2}$ compositions at low activation temperatures. It follows from this, that such complexes are not active in the direct chemisorption of sulfur dioxide. At the same time, $\mathrm{MgFe}_{2} \mathrm{O}_{3}$ phase and solid solution of $\mathrm{Fe}^{3+} / \mathrm{MgO}$ (He et al., 2008; He et al., 2004; Eid and Ammar, 2011; Yao et al., 2008), in which iron ions are difficult to reach, are mainly formed in $\mathrm{Fe}_{2} \mathrm{O}_{3}-\mathrm{MgO}$ system. Nevertheless, activity of these samples was high. $\mathrm{Fe}_{2} \mathrm{O}_{3}-\mathrm{Al}_{2} \mathrm{O}_{3}$ system, where iron complexes are on the surface, possessed greater activity (Yao et al., 2008; Komarov, 1977). As a result of the carried out researches we can make the following conclusion: a lot of surface and volume structures differing by symmetry of the coordination sphere of iron ions are formed in the course of iron supported systems thermal activation. The thermal phosphoric slag also contains minor amounts of the surface structures, but the main part of iron is in its matrix of complex formations. The adsorption of sulfur dioxide on $\mathrm{Fe}_{2} \mathrm{O}_{3}$ - supported systems and tailings is carried out on the multi-stepped mechanism. The part of $\mathrm{SO}_{2}$ is chemisorbed on the surface of iron complexes with formation of sulfite structures (Yanan et al., 2014; Ferrizz et al., 2002; Centi et al., 1992; Kirk-Othmer, 1991; Kaldybayev et al., 2013). We suggest that in the presence of moisture these surface complexes are oxidized by atmospheric oxygen till the corresponding sulfates. The main part of sulfur dioxide is chemisorbed on strongly basic centers of magnesium, calcium and aluminum oxides with formation of apparently similarly corresponding (surface) sulfates (He et al., 2004; Ya-nan et al., 2014; Ferrizz et al., 2002; Shakirov et al., 2013). The iron complexes at high temperatures actively participate in the activation of molecular oxygen, with the help of which catalytic oxidation of $\mathrm{SO}_{2}$ to $\mathrm{SO}_{3}$ and metal sulfites into the corresponding sulfates is carried out (He et al., 2004; Shakirov et al., 2013; Shakirov et al., 2012). Highly dispersed iron oxides of non-stoichiometric composition play the great role in the chemisorption and catalytic oxidation of $\mathrm{SO}_{2}$. 
Super-stoichiometric oxygen that was in the composition of these oxides is the active participant in the oxidation reaction of $\mathrm{SO}_{2}$.

According to the analysis results of the mineralogical composition produced by calcined at $500{ }^{\circ} \mathrm{C}$ and the saturated $\mathrm{SO}_{2}$, as shown by immersion researches aggregate carbonategoethite-mica - limonite grains are dominated $(\approx 85 \%)$. In these grains calcite $(\mathrm{Np}<1,519)$ are clearly fixed by the places.

The grains of quartz $(\mathrm{Ng}-\mathrm{Np} \approx 0,01$ è 1,570 $>N g>N p>1,531)$ are present in a small quantities $(\approx 5 \%)$.

In the sorbent saturated by sulphate ions, sulphate grains with optical properties, characteristic for botriogen are also established by immersion analysis:

$\mathrm{Ng}=1,574 \pm 0,005$

$\mathrm{Ng}=1,5250,005$ and

$\mathrm{Ng}-\mathrm{Np}=0,049 \pm 0,01$

These data for botriogen determined by us well fit with the literature data by the optical characterization of this mineral [000]:

$\mathrm{Ng}=1,579-1,582$,

$\mathrm{Np}=1,522-1,523$ and

Ng-Np - 0,055-0,059.

Number of clearly botriogen grains in immersion preparations makes about $10 \%$. However, it is possible that the smallest botriogen inclusions are also present in the aggregate carbonate-limonite grains, which is optically veiled by limonite that does not reduce their chemical activity.

Limonite (goethite and hydrogoethite) is established by the brown color in the reflected light. Besides, nontransparent black grains are present in a small quantites, which likely are wustite (Shakirov et al., 2012) or iocite (FeO). Latter by literature data is unstable and is easily transformed into maghemite and magnetite (Shakirov et al., 2012). By the results of conducted researches, we can conclude that probably, the presence of minerals such as ankerite, dolomite and pyrite in thermo - phosphoric slags plays important role for the formation of activity of sorbent.

During the calcination, at the expense of these minerals oxides $\mathrm{MgO}, \mathrm{FeO}$ and $\mathrm{Fe}_{2} \mathrm{O}_{3}$ are formed in thermo - phosphoric slags, which interacting with $\mathrm{SO}_{2}$ and vapors of $\mathrm{H}_{2} \mathrm{O}$ form sulphates. It must be emphasized that in our experiments, the formed $\mathrm{SO}_{2}$ during the decomposition of pyrite does not lose similarly vapor $\mathrm{H}_{2} \mathrm{O}$ and $\mathrm{CO}_{2}$ during the decomposition of carbonates, and is directly bind as sulphates in thermo - phosphoric slags. A such process character occupies place, apparently, when the sorbent is calcined at $500{ }^{\circ} \mathrm{C}$ for 2 hours. With increasing of calcining time up to 3-4 hours, sorbent loses its activity. We can assume that during the first two hours of calcining at the expense of pyrite and ankerite, iocite (FeO) is mainly formed, which during the longer calcining is transformed into maghemite $\left(\mathrm{Fe}_{2} \mathrm{O}_{3}\right)$ and magnetite $\left(\mathrm{Fe}_{2} \mathrm{O}_{4}\right)$ (Shakirov et al., 2012). The last two minerals do not practically interact with $\mathrm{SO}_{2}$ at a temperature of $200{ }^{\circ} \mathrm{C}$, apparently, explains by the decrease of the sorption properties of thermo phosphoric slag, calcined for more than 2 hours.

As far as during cleaning of gas from sulphur dioxide, metal oxides of sorbent are converted into the corresponding sulphates, and the degree of cleaning is sharply reduced. Regeneration of sorbent is achieved by thermal catalytic decomposition of sulphates in the air. Regeneration temperature is gradually increased with increasing multiplicity of regeneration. Sorbent withstand a large number of thermal regeneration.

The decomposition reaction of the formed sulphates is one of the main processes, and at this the reactive oxides are formed on the surface of the sorbent. If a gas, containing sulphur dioxide is subjected to the cleaning, and concentrated gases can be obtained as a result of intensive decomposition of the formed metal sulphates, which are suitable for the production, for example sulphuric acid. At such statement of tasks, the sorbent can be used for many times, but the decomposition temperature of the metal sulfates is unequal.

The experiments by cleaning of gas mixture with the use of intermediate regenerations were carried out at a temperature of $200^{\circ} \mathrm{C}$ using a sorbent, calcined at $500{ }^{\circ} \mathrm{C}$. The initial degree of cleaning was $50 \%$, a reducing time of the degree of cleaning is below $10 \%$ at 55 min., while sulphur capacitance of sorbent was $6.82 \%$ wt. The spent sorbent was subjected to regeneration at a temperature of $500{ }^{\circ} \mathrm{C}$ for 2 hours. After such treatment of the spent sorbent, it proved to be unsuitable for cleaning of subsequent portions of the gas. 
This phenomenon is apparently stipulated by the following. Basis of acting thermo phosphorus slag when cleaning are oxides of metals such as $\mathrm{Al}$, Ca and $\mathrm{Mg}$, which when cleaning above mentioned oxides, interacting with sulphur dioxide in the presence of oxygen and water vapor are converted into sulphates. Such sulphated thermo - phosphoric slag can be applied as a precious coagulant for wastewater treatment.

\section{CONCLUSION}

Influence of the preliminary activation process parameters on the quality of the gas emission purification from sulfur dioxide at the calcination temperatures (in the range from $100^{\circ} \mathrm{C}$ to $800^{\circ} \mathrm{C}$ ), presence of water vapors in the gas mixture ( 0 and $10 \%$ ), concentration of sulfur dioxide entering for the purification of gas mixture (in the range from 0.3 to $0.7 \%$ by vol.) has been studied. The chemisorption of sulfur dioxide with formation of sulfites, which pass into the sulfates in the air, occurs at the optimal parameters of the process. At the high temperatures, the chemisorption process is intensified at the expense of catalytic participation of metal oxides.

Thus, the possibility to purify waste (including flue) industrial gases from sulfur dioxide using the thermophosphorus slag as the sorbent has been studied. Regeneration of the spent sorbent and its futher use is the following perspectives of research work.

\section{ACKNOWLEGEMENTS}

We would like to express our gratitude for support from the M.Auezov SKSU and Committee of science of the Ministry of Education and Science of the Republic of Kazakhstan (No. 275 of February 04, 2014).

\section{REFERENCES}

1. Ling, Z., Xinyong, L., Qidong, Z., Zhenping, Q., Deling, Y., Shaomin, L., Xijun, H. and Guohua, C., Synthesis, characterization and adsorptive performance of $\mathrm{MgFe}_{2} \mathrm{O}_{4}$ nanospheres for $\mathrm{SO}_{2}$ removal. 2010; 184(1-3): 704-709, DOI: 10.1016/j.jhazmat. 2010.08.096). Journal of Hazardous Materials.

2. Jin-an, W., Ze-lin, Z. and Cheng-lie, L., Pathway of the cycle between the oxidative adsorption of $\mathrm{SO}_{2}$ and the reductive decomposition of sulfate on the $\mathrm{MgAl}_{2}-\mathrm{XFe}_{\mathrm{x}} \mathrm{O}_{4}$ catalyst. 1999; 139(1): 3141, DOI: 10.1016/S1381-1169(98)00186-1). Journal of Molecular Catalysis A: Chemical.

3. Bennici, S., Gervasini, A., Ravasio, N. and Zaccheria, F., Optimization of tailoring of $\mathrm{CuO}_{x}$ species of silica alumina supported catalysts for the selective catalytic reduction of $\mathrm{NO}_{x} .2003$; 107(22): 5168-5176 DOI: 10.1021/jp022064x). Journal of Physical Chemistry B.

4. Smirnov, M.Y., Kalinkin, A.V., Pashis, A.V., Sorokin, A.M., Noskov, A.S., Kharas, K.C. and Bukhtiyarov, V.I., Interaction of $\mathrm{Al}_{2} \mathrm{O}_{3}$ and $\mathrm{CeO}_{2}$ surfaces with $\mathrm{SO}_{2}$ and $\mathrm{SO}_{2}+\mathrm{O}_{2}$ studied by $\mathrm{X}$ ray photoelectron spectroscopy. 2005; 109: 11712-11719, DOI: 10.1021/jp0508249). Journal of Physical Chemistry.

5. Bretschneider, B. and Kurfurst, J., Air pollution control technology. Transl. from English. Leningrad, Chemistry Press, 1989.

6. Li, J., Hao, J., Fu, L. and Zhu, T., High efficiency of noble metal and metal oxide catalyst systems for the selective reduction of NO with propene in lean exhaust gas. 2004; 30. DOI: 10.1023/ B:TOCA.0000029732.81475.09). Topics in Catalysis.

7. Chmielarz, L., Kus'trowski, P., Dziembaj, R., Cool, P. and Vansant, E.F., Catalytic performance of various mesoporous silicas modified with copper or iron oxides introduced by different ways in the selective reduction of NO by ammonia. 2006; 62: 369. DOI: 10.1016/ j.apcatb.2005.09.004). Applied Catalysis B: Environmental.

8. He, C., Paulus, M., Chu, W., Find, J., Nickl, J.A and Koehler, K., Selective catalytic reduction of $\mathrm{NO}$ by $\mathrm{C}_{3} \mathrm{H}_{8}$ over $\mathrm{CoO}_{\chi} / \mathrm{Al}_{2} \mathrm{O}_{3}$. An investigation of structure-activity relationships. 2008; 131: 305. DOI: 10.1016/j.cattod.2007. 10.024). Catalysis Today.

9. He, H., Zhang, C. and Yu, Y., A comparative study of $\mathrm{Ag} / \mathrm{Al}_{2} \mathrm{O}_{3}$ and $\mathrm{Cu} / \mathrm{Al}_{2} \mathrm{O}_{3}$ catalysts for the selective catalytic reduction of $\mathrm{NO}$ by $\mathrm{C}(3) \mathrm{H}(6)$. 2004; 90: 191. DOI: 10.1016/j.cattod.2004.04. 026). Catalysis Today.

10. Eid, Kh.M. and Ammar, H.Y., Adsorption of $\mathrm{SO}_{2}$ on Li atoms deposited on MgO (1 0 0) surface: DFT calculations. 2011; 257(14): 6049-6058, DOI: 10.1016/j.apsusc.2011.01.122). Applied Surface Science.

11. Przepiórski, J., Czy¿̇ewski, A., Kapica, J., Moszyñski, D., Grzmil, B., Tryba, B., Mozia, S. and Morawski, A.W., Low temperature removal of $\mathrm{SO}_{2}$ traces from air by $\mathrm{MgO}$-loaded porous carbons. 2012; 191: 147-153. DOI: 
10.1016/j.cej.2012.02.087). Chemical Engineering.

12. Yao, S., Pan, H., Zhang, Y. and Li, W., Promotion of $\mathrm{MgO}$ addition on $\mathrm{SO}_{2}$ tolerance of $\mathrm{Ag} / \mathrm{Al}_{2} \mathrm{O}_{3}$ for selective catalytic reduction of $\mathrm{NO}_{x}$ with methane at low temperature. 2008; 9(5): 796, DOI:10.1016/j.catcom.2007.09.002). Catalysis Communications.

13. Komarov, V.M., Adsorbents and their properties. Minsk. Science and Technology Press, 1977.

14. Ya-nan, S., Tao, L., You, T., Li, C. and Shan, H., Effect of sulfation on the performance of $\mathrm{Fe}_{2} \mathrm{O}_{3}$ $\mathrm{Al}_{2} \mathrm{O}_{3}$ catalyst in catalytic dehydrogenation of propane to propylene. 2014; 244: 145-151, DOI:10.1016/j.cej.2014.01.047). Chemical Engineering.

15. Ferrizz, R.M., Gorte, R.J. and Vohs, J.M., TPD and XPS investigation of the interaction of $\mathrm{SO}_{2}$ with model ceria catalysts. 2002; 82: 123-129, DOI: 10.1023/A:1020512713021). Catalysis Letters.

16. Centi, G., Passarini, N. and Perathoner, S., Combined DeSO $/$ DeNO $_{x}$ reactions on a copper on alumina sorbent-catalyst. 1 . Mechanism of sulfur dioxide oxidation-adsorption. 1992; 31: 1947-1955, DOI: 10.1021/ie00008a016). Industrial and Engineering Chemistry Research 17. Kirk, O., Encyclopedia of Chemical Technology. New York, 1991.

18. Kaldybayev, A.B., Mirzayev, A.A., Zhantasov, K.T., Shakirov, B.S. and Baklanov, M.R., Using of phosphoric industry wastes as a sorbent for purification of sulfur-containing gases. 2013; 393-398. In the Proceedings of the International conference.

19. Shakirov, B.S., Kaldybayev, A.B., Mirzayev, A.A., Kaldykozov, T.A. and Saipov, A., A method of sorption purification of waste gases from sulfur dioxide. Kazakhstan Patent 2013; 79339.

20. Shakirov, B.S., Kaldybayev, A.B., Mirzayev, A.A., Development of technologies for adsorption-catalytic-chemisorption purification of gas emissions from sulfur dioxide. 2012; (No. 1492, pp. 77). Research report. 